\title{
História Oral e História Pública: Os caminhos para a posse da terra na Favela Vila Operária
}

\section{Oral History and Public History: The ways to the land ownership in Vila Operaria slum}

\author{
Denize Ramos Ferreira* \\ denigaia.denize@gmail.com
}

\section{Resumo}

No final do século XIX, início do século XX, embora ainda constituíssem locais pouco numerosos, as favelas já se apresentavam como áreas que preocupavam. A favela Vila Operária, surgiu em Duque de Caxias, na Baixada Fluminense, a partir da ocupação de um morro não habitado. Preocupava alguns políticos locais além do legítimo proprietário por não conseguir reaver sua propriedade sob o controle dos migrantes. Estes, desde o início, fortaleciam sua identidade social por meio de um novo enraizamento que se sustentava na ocupação da terra. A Prefeitura negociou em segredo a compra deste morro a partir de 2008. Quando tornei esta história pública em 2013, a Prefeitura foi obrigada a reconhecer, por interferência do Poder Judiciário, que os moradores tinham direito à posse desta terra. A História Oral e sua publicação tornaram reais o sonho de 1958.

Palavras-chave: favela, História Oral, História Pública

\begin{abstract}
In the late 19th century, early 20th century, though still constitute little places numerous, the slums are already presented as areas that concerned.

The Vila Operária slum arose in Duque de Caxias, in the Baixada Fluminense, from the occupation of a hill not inhabited. Worried some local politicians beyond the rightful owner for not being able to get your property under the control of migrants. These, from the beginning, strengthened their social identity through a new rooting that supported him in occupation of the land. The city negotiated in secret purchase this hill from 2008. When I made this public history in 2013 , the city was forced to acknowledge, by interference of the judiciary, that the villagers were entitled to the possession of this land. Oral history and its publication made real the dreams of 1958.
\end{abstract}

Keywords: slum, oral history, public history

\footnotetext{
* Possui graduação em História. Atualmente é pesquisadora associada à Universidade do Estado do Rio de Janeiro (UERJ) pelo Laboratório de Estudos das Diferenças e Desigualdades Sociais (LEDDES). Fez parte do Laboratório de Estudos do Tempo Presente (UFRJ). Mestre em História Comparada pela Universidade Federal do Rio de Janeiro (UFRJ) e professora de História. Tem experiência na área de História com ênfase em História do Brasil, atuando principalmente nos seguintes temas: Baixada Fluminense, memória, vulnerabilidade social, Ditadura Civil- Militar, favela, partido comunista, clientelismo, periferia, desterritorialização. Pesquisa atualmente a atuação do Partido Comunista Brasileiro em favelas da periferia do Rio de Janeiro por meio da metodologia de História Oral e História Pública.
} 
Artigos

\section{História Oral e História Pública: Os caminhos para a posse da terra na Favela Vila Operária}

A Favela Vila Operária localiza-se em um morro, no bairro Parque Felicidade, no $1^{\circ}$ Distrito de Duque de Caxias. Os primeiros registros de sua ocupação são do ano de 1954. A maioria dos novos moradores veio do nordeste do Brasil e, em número menor, da própria região sudeste, inclusive do interior do Estado do Rio de Janeiro, em busca de emprego e melhores condições de vida, mas não foram diretamente para essa localidade. Eles tentavam antes a vida na cidade do Rio de Janeiro. Muitos que chegavam entre 1930 e 1950 encontravam nas favelas a moradia que buscavam. Aproximadamente 12,3\% permaneciam nelas, com o restante encaminhando-se para o subúrbio.

As favelas, como afirma Marcos Alvito, "são basicamente a solução popular possível para o problema da habitação e do transporte.” (ALVITO, 2010.) ou seja, é uma forma urbana e espontânea para aproximar o trabalhador das áreas de produção, reduzindo seus gastos. Mas os membros do Estado não pensavam assim. Os cortiços e as favelas eram compreendidos como áreas de pobreza e criminalização, um antro de vagabundagem, prostituição, insalubridade, propenso a epidemias, propagador de vícios, ou seja, era um lugar só para gente da "classe perigosa". (VALLADARES, 2009, p.24 e p.26). Portanto, a falta de condições dignas para seus habitantes era uma ameaça à ordem pública e moral da sociedade, uma vez que o próprio ambiente legitimaria possíveis revoltas sociais. Os moradores dessas localidades, na verdade, eram e são vítimas de um pró-processo de homogeneização, (PEREIRA, 2000, p.12) sustentando estereótipos que, por consequência, são vistos pelos habitantes da cidade formal, pelo desconhecimento, com preconceito.

Devido a essa imagem negativa desses bolsões de pobreza urbanos, o controle sobre tais áreas tornouse intenso desde a reforma urbana realizada por Pereira Passos, prefeito entre os anos de 1902 e 1906. Daí em diante, esse processo foi contínuo, regulando o crescimento da habitação popular urbana, tendo como uma de suas consequências a expulsão dos mais pobres para a periferia, da qual Duque de Caxias fez parte.

A favela Vila Operária tinha como especificidade o fato de que os moradores não tinham escritura de suas propriedades. Tais especificidades são conhecidas somente por quem está dentro dela, seja trabalhando, como no meu caso, ou pelo próprio morador. Passar em frente de uma favela com certa frequência, morar ao lado de uma, ler reportagens nos jornais não nos permite identificar as condições de vida efetivas dentro da localidade.

Observo que a própria definição do morador de favela, favelado, que já se falava na década de 1950, criava uma imagem negativa associada a pobreza, falta de saneamento, à insalubridade na qual seus habitantes viviam, justificando assim as ações arbitrárias dentro da localidade por parte do Estado que segundo o mesmo também seriam ações civilizatórias.

Com a presença informal no mercado de trabalho e, portanto, desconectada da luta operária, a categoria favelado emprestava uma identidade coletiva aos excluídos de determinada área geográfica, dando-lhes maiores possibilidades de lutarem por direitos sociais, uma vez que criavam uma identidade social e, dessa forma, apesentavam para a sociedade quem eram eles, em que condições viviam e por que buscavam soluções para seus problemas locais.

A imagem construída através das décadas, precisamente a partir de 1957, sobre favela, está associada à questão social, mas também havia (e ainda há) um conceito que o estado de miserabilidade, no qual viviam, induzia à falta de consciência política, fácil manipulação ideológica e subserviência. O que discordo, pois entendo que esse grupo tem um enorme potencial de luta e que conforme essa identidade social vai se formando, o morador da favela vai se organizando, pois, a meu ver, começa a compreender que sozinho não será escutado.

O pobre é uma ameaça pelo potencial destrutivo quando se apresenta na forma coletiva, fora do ambiente de trabalho, ou seja, sem a supervisão direta da autoridade disciplinar; é ainda uma ameaça à sua própria saúde e à dos outros habitantes da cidade: seus corpos sujos e fracos seriam vítimas fáceis de doenças; o lugar onde se abrigavam para descansar constituiria o meio ambiente mais propício à produção de miasmas e o aparecimento de doenças epidêmicas. Este é o conceito que a conjuntura da favela suscitou por décadas e que se identifica até o presente. 
Não me furto, porém, a reconhecer que as favelas têm alguns traços em comum, mas ainda assim não caracteriza um processo hegemônico de favelização, embora o próprio Estado já o tenha feito considerando as favelas como um todo, ao ter julgado que o aspecto físico do lugar - com suas casas pobres, a insalubridade, a falta de saneamento, dentre outras características - transformava esse espaço urbano em uma patologia social, uma lepra estética. Este não era um conceito construído popularmente, mas por órgãos de Estado e organizações civis.

A ideia de que a favela era uma área que necessitava de controle político, mas também que tivesse serviços urbanos para favorecer as mínimas condições de reprodução da força de trabalho para ser aproveitada devidamente na área urbana, já aparece enunciada pela Fundação Leão XIII, criada pela Igreja Católica em 1947.

A constituição da favela como um problema ganhou força no momento em que a nossa república se estruturava no final do século XIX, início do século XX. Embora ainda constituíssem espaços pouco numerosos, já se apresentavam como um espaço geográfico que despertava preocupação como a Vila Operária, que ocupando o espaço de um morro não habitado, preocupava políticos e o legítimo proprietário por ter moradores que desde o começo buscavam fortalecer sua identidade social e econômica.

O morro no qual a Vila Operária está localizada foi ocupado no processo de expansão urbana, ocorrido na década de 1950. Entre 1954 e 1958, quando os primeiros moradores chegaram, segundo os relatos orais de Maria do Carmo Portela e Ivete Assis Santos, que fazem parte do primeiro grupo de ocupação, cada um se estabelecia no terreno de acordo com o espaço que precisava. Afirmaram que, como era uma área desabitada, buscaram os melhores lugares para construir, como a Rua da Mina, justamente por ter uma fonte de água potável disponível, que acabou se transformando em poço artesiano.

José Batista Pereira, morador local, contou que os caminhos no morro eram muito estreitos, dificultando a passagem. Havia um grande capinzal, no qual pastavam cavalos e vacas e uma vacaria que vendia leite. Não havia casas de alvenaria, barracos de madeira ou calçamento, tão pouco divisão em terrenos, o que caracterizava um local sem donos para os primeiros moradores que ocuparam a região.

Nesse depoimento, meu entrevistado afirmou que "O morro era abandonado. Não era de ninguém". Justifica-se dessa maneira que não faziam nada ilegalmente. Não havia dono declaradamente para eles; portanto, apropriar-se de uma parte daquela terra não significaria cometer qualquer tipo de infração socialmente.

Esse relato está atrelado aos conflitos iniciais pelos quais os primeiros moradores passaram. Mas narrar esses conflitos poderia confirmar a ocupação ilegal de uma propriedade, o que os ligaria a um tipo de marginalidade: a dos que expropriam os bens de outrem. Poder-se-ia atribuir uma culpabilidade coletiva que acrescentaria à localidade, além da condição de pobres urbanos, mais um estigma: o de se "encontrarem permanentemente fora da sociedade, pois não participam dos valores comuns que definem a própria sociedade." Eram trabalhadores migrantes, que deixaram parentes, mulher ou marido e filhos, emprego e vinham tentar um novo caminho, buscavam um lugar para construir uma moradia, portanto seu estado de vulnerabilidade já criava muitas barreiras para serem transpostas. Essa representação mnemônica do passado era uma forma de buscar a valorização em relação à sociedade em geral.

No início desta pesquisa, quando elaborei fichas para que os moradores preenchessem com dados sobre a história inicial da Vila Operária, um fato me chamou a atenção: nessas fichas, meus entrevistados não escreveram que a ocupação inicial foi na propriedade de Genack Chadrycky, o legítimo dono perante o Estado nem relataram os conflitos que existiram, mas sim que José de Jesus, um morador do bairro Parque Felicidade, no qual está localizado o morro, distribuía terrenos que não lhes pertenciam e que alguns novos moradores compraram suas propriedades de algum morador mais antigo ou do próprio José de Jesus. Portanto há uma memória subterrânea na localidade. Ou seja, uma memória não dita, que está em silêncio e que, se trazida da escuridão do passado, despertará lembranças censuradas e talvez indizíveis até hoje.

Nesse caso, o trabalho de solidificação da memória foi tão importante que impossibilitou que outra narrativa aparecesse. (POLLAK, vol. 5, n. 10, 1992, pp. 10-11). Fui buscar na memória do advogado da família Chadrycky, proprietária legal desta área, dados para comparar com a memória dos moradores e de Jane de Jesus, filha de José de Jesus, já falecido, que é citado nos relatos orais como o organizador da ocupação desse morro. 
Artigos

Meu objetivo com essa comparação era identificar as vivências diferenciadas das realidades que encontramos nos relatos orais. Queria encontrar o fio condutor dessas memórias, fosse a individual ou a coletiva, a fim de compreender as relações de poder entre os desiguais. Nos relatos supracitados, identifiquei que esse fio condutor foi a terra para moradia e o estabelecimento de condições mínimas para habitá-la. Ela era e é o grande elemento agregador dos moradores, o que construiu as relações de proximidade entre eles, o que provocou lutas jurídicas e relações políticas clientelísticas. Toda uma estrutura familiar, de amizade e de trabalho, foi modificada. Era necessário, neste novo espaço geográfico, que neste caso é o morro que deu origem à Favela Vila Operária, demarcar um novo território simbólico diferenciado, um lugar que lhes favorecesse o estabelecimento de uma nova identidade, na qual pudessem congregar as raízes, que ainda não haviam sido arrancadas na tentativa de um auto reconhecimento.

A terra foi elemento agregador para esses moradores, por não terem nenhuma infraestrutura na fase inicial de ocupação, organizavam mutirões, nos fins de semana, utilizando o modelo participativo como narrou D. Belinha (moradora desde a década de 1950). Disse-me que os moradores construíram as habitações com madeira, zinco, sapê ou com alvenaria. Chegando à região em 20 de março de 1956, com seu pai e seis filhos, encontrou muita formiga, cobras, aranhas e um grande brejo na parte que pôde ocupar. Isso caracterizava a região como insalubre, sem qualquer tipo de saneamento. O local era um beco. Mas ela ficou. Havia partido de Paraíba do Sul e não voltaria.

Os novos moradores aplainaram as ruelas de barro com enxada e quem conseguia, puxava "bicos de luz”. Construíram a Igreja Católica de Nossa Senhora do Perpétuo Socorro, que ainda existe no alto do morro, e a escola, que, antes de a prefeitura assumir, funcionava com professoras voluntárias, segundo relato oral de Maria Luiza Brandão, que foi morar em 1959 na localidade. Chamava-se Escola Municipal Itaperuna e hoje se chama Escola Municipal Vila Operária. A prefeitura assumiu a escola, mas nossa colaboradora não soube precisar quando. O local era desprovido de tudo na década de 1950: água, luz, esgoto, arruamento, transporte, posto de saúde e escola. Não havia violência, tráfico de drogas ou crimes.

O modelo participativo adotado apontou para novas direções como a organização do Centro PróMelhoramento do Parque Felicidade, fundado em 12 de janeiro de 1959, por José de Jesus, cujo objetivo, segundo relatos, era buscar atender aos interesses coletivos dos habitantes do morro e do bairro Parque Felicidade no qual estava. Esse centro comunitário, na década de 1980, tornou-se a primeira Associação de Moradores, sendo liderada por Davino Miguel da Rocha, eleito pelos moradores. Obtiveram muitas conquistas com essa organização, dentre as quais água para o morro. Jane de Jesus, filha de José de Jesus, contounos que nesses mutirões na década de 1960, as mulheres faziam a comida (café, lanche, angu ou sopão) e os homens trabalhavam.

Para entretenimento, havia o campo de futebol no qual os moradores jogavam pelada. Era o Campo dos Unidos, nome bem significativo para a realidade vivida naquele momento. No carnaval, saía o Bloco Sobe-Desce que, cruzando a favela, conseguia unir os moradores e trazer alegria diante das dificuldades vividas. O nome é referência ao percurso que o bloco fazia subindo e descendo as ruas do morro. As dificuldades enfrentadas por todos, criou uma unidade no morro. A solidariedade era a característica desses primeiros moradores.

Segundo o relato de José Correia da Rocha, advogado da família de Genack Chadrycky, o legítimo proprietário, não se sustentam as alegações dos primeiros moradores que ocuparam o morro. Eles afirmaram que o fizeram porque o local não tinha dono. Para ele, tal afirmação foi e é inverossímil. O proprietário era judeu russo, negociante de pedras preciosas no Brasil e extremamente rico. Não morava em Duque de Caxias, mas na cidade do Rio de Janeiro. Tinha muitas propriedades em diversos lugares. E o local no qual se encontra a Vila Operária e o cemitério Nossa Senhora das Graças pertencia a ele, mas realmente não era ocupado nem cercado, era simplesmente um morro, como os moradores narraram em suas entrevistas.

Logo depois que as invasões começaram, precisamente em 1960, o proprietário contratou uma empresa imobiliária, cujo corretor do espólio era Geneciano Luz, que organizou o loteamento do morro e o transformou em Parque Genack Chadrycky. O preço era muito barato. Não havia critério para a venda, bastava morar no local ou querer morar. Aparece na planta do loteamento de 1975 o nome de Jorge A.S Luz como proprietário. Não encontrei dados para esclarecer tal fato. O objetivo, ao vender os lotes para os 
invasores ou para qualquer pessoa que quisesse comprar, era que o proprietário não perdesse dinheiro, pois mesmo com o preço baixo, teria algum lucro.

O loteamento só começou a ser realizado em 1960, portanto, o relato mnemônico de quem chegou à localidade antes reproduziu o início do processo. Os que chegaram depois de janeiro de 1960 já encontravam na entrada do loteamento agentes imobiliários. Mas nenhum dos nossos entrevistados cita esse fato, independente da data que tenham chegado ao morro para ocupá-lo.

As lembranças comuns "nos permitem afirmar que, na realidade, nunca estamos sozinhos", e isso corrobora para a construção de uma identidade social, como uma cumplicidade de memória. Ela é estabelecida na medida em que o indivíduo percebe que o todo pode respaldar suas ações. Há um deslocamento de ponto de vista, dependendo da necessidade implícita ou explícita em determinado grupo.

Essa unicidade mnemônica criou uma ideia de continuidade de ação por parte do morador da Vila Operária em relação àquele que tentava impedir a posse sobre a terra. A memória narrada por meio do depoimento oral demonstra que essa população não aceitava pacificamente a imposição de um pagamento para aquilo que julgava ser seu por direito. A luta foi de todos. Essa memória permanece até os dias atuais, pois tem apoio externo, ou seja, refere-se a um lugar socialmente marcado, como afirma Riccoeur (2007))

Encontrei a planta desse parque, elaborada em 1975, por Rogério Mitraud, engenheiro da prefeitura. A data é posterior ao período da ocupação, mas, ainda assim, representava os loteamentos da Vila Operária. Conversei, com ele, a fim de compreender por que os lotes, na planta, apresentavam terrenos com medidas tão diferentes entre si e com metragens que mal dariam para construir um cômodo. Como, por exemplo, um terreno com 6,95m X 2,5m X 6,95m X 3,5 e outro com 22 m X 39 m X 35 m X 29 m.

O engenheiro Mitraud contou que elaborou a planta em 26 de setembro de 1975 para a prefeitura de Duque de Caxias, no governo do Coronel Renato Moreira da Fonseca. O objetivo era delimitar o terreno do cemitério, uma vez que a prefeitura o havia ocupado ilegalmente para enterrar os mortos. $\mathrm{Na}$ época, esse prefeito cedeu à Funerária Duque de Caxias a concessão dos enterros. O engenheiro também calculou as metragens das sepulturas para o melhor aproveitamento do espaço geográfico do local.

O advogado José Correia da Rocha disse que a prefeitura cercou a área com arame farpado, ilegalmente, na década de 1960. Este processo afastava os cavalos, bois e vacas, mas não os porcos, que passavam por baixo da cerca e fuçavam as covas, causando grande problema de insalubridade no local. Somente na década de 1970, o cemitério foi regularizado.

Solicitei ao advogado José Correia da Rocha que explicasse por que tamanha disparidade na metragem dos terrenos em uma área de 180.000,00 m2 que estava à venda sob a forma de loteamento. Disse-nos que o loteamento fora criado com autorização da prefeitura, após a ocupação dos moradores. Portanto, o que já estava feito, ficou. Por isso as diferenças entre a metragem dos lotes. Alguns moradores ocuparam áreas maiores que outros, por terem a família maior, por possuírem algum capital que poderiam utilizar para fazer sua construção, ou por já estarem pensando em venda no futuro. $O$ agente imobiliário, com a planta na mão, identificava o lote que o invasor ocupava e fazia a proposta de compra e venda.

Foram vendidos, aproximadamente, 50 a 60 lotes com outorga da escritura. Mas aí os problemas começaram. Muitos moradores foram para a justiça brigar pela posse da terra. Muitos políticos e líderes locais diziam para os moradores que não comprassem a propriedade, pois seria deles. Inclusive, ofereciam terrenos em troca de votos. Um desses líderes do local era José de Jesus.

Segundo este advogado, entre duas e três décadas atrás, ou seja, por volta de 1980 e 1990, os conflitos pararam. Antes ocorriam constantes manifestações nas ruas da Vila Operária em busca do que consideravam seu direito, ou seja, a propriedade da terra sem o pagamento por ela. Portanto, para os moradores, publicar sua situação para a sociedade era uma forma de empoderar e politizar historicamente os que não eram escutados. Entendemos que o medo de perder a terra os levou às manifestações constantes. Havia uma crise de legitimidade. As relações de poder, para o pobre urbano, e especificamente este da periferia da Baixada Fluminense, estavam atreladas à situação histórica de dependência. Aníbal Quijano escreveu:

Em todas as sociedades modernas e em cada momento observou-se a existência de uma categoria de pessoas mais ou menos permanentemente excluídas do núcleo principal do trabalho e que, devido as suas rendas insuficientes, não tinham acesso ao consumo de bens e serviços (...) (QUIJANO, Aníbal, 1973, P. 141) 
Artigos

Entendendo que, como já eram expropriados por pertencerem aos estratos mais baixos e não possuírem diversos direitos, havia um sentimento de estarem sendo explorados. Lutar pela terra seria uma forma de autoafirmação social. Habitavam, em sua maioria, construções sem licenciamento e em terreno de terceiros. Não tinham condições de pagar pela terra e ainda eram influenciados por políticos ou candidatos a uma vaga no parlamento a não aceitar qualquer acordo que implicasse gasto. Esta relação política era "temperada por uma série de atividades e relações paralelas, desde o ensino das etapas burocráticas necessárias para conseguir documentos até conselhos (...). Uma espécie de recompensa pela exploração sofrida”.

O advogado José Correia da Rocha atribui as manifestações à manipulação política na localidade. Entendeu que a Vila Operária era um "barril de pólvora", por volta de 1960. Não compreendeu o morador como alguém capaz de agir por si mesmo, defendendo seu lugar de moradia, mas alguém que reagiu por ter sido induzido politicamente.

Considero dois pontos importantes, neste momento, que nos ajudam a compreender o que era, na verdade, o "barril de pólvora" que José Correia da Rocha nos cita. Um, que os moradores desejavam o título de propriedade, pois a perenidade de sua presença na área não lhes garantia que as autoridades, ligadas ao Estado, os deixariam ficar. Poderiam ser removidos, se não pagassem.

Outro ponto relevante foi a preponderância de algumas profissões no local. Moravam ou o frequentavam muitos ferroviários, que possuíam um sindicato forte, principalmente na década de 1950. Demistoclides Batista, o "Batistinha", que era presidente do Sindicato dos Ferroviários da Leopoldina, localizado na cidade do Rio de Janeiro, filiado ao Partido Comunista Brasileiro, visitava com muita frequência a Vila Operária. Mas, na própria região, morava Uberahy Gonçalves, líder ferroviário em Duque de Caxias, também filiado ao PCB. Moravam nesse morro muitos estivadores do Cais do Porto, que também possuíam um sindicato forte e com muitos membros do PCB. Identificamos, também, rodoviários sindicalizados nos relatos de meus entrevistados.

Não descarto a manipulação ideológica de uma parte dos moradores por algum pretenso candidato a cargo público ou até pelo próprio Estado; mas limitar a ação dos moradores exclusivamente ao fato de que não possuíam consciência política, é negar efetivamente que a Vila Operária, independente da vontade de José de Jesus, que insistia no uso desse nome, era um lugar de trabalhadores e de muitos com consciência política. Carone esclarece:

Nas cidades, a luta da classe operária vinha ampliando-se desde 1952. Com o crescimento do movimento sindical, a maioria dos sindicatos foi expelindo velhos pelegos que haviam dominado as organizações operárias durante o estado Novo. Toda uma geração recém-formada de líderes operários foi-se forjando, fazendo com que muitas organizações sindicais se tornassem fortes. (...) (CARONE, V.3,1982, p. 22.)

A ascensão do movimento sindical se dava, no entanto, dentro de determinados limites. (...) Com exceção de determinadas categorias, que dependem do sindicato para trabalhar (estivadores e marítimos) ou de algumas outras mais politizadas (ferroviários da Leopoldina, por exemplo) a maioria dos operários ficou à margem da sindicalização.

O relato de José Correia da Rocha traz à tona a categorização de seus moradores, a partir do olhar da burguesia, na medida em que reconhece que onde houver classe pobre, haverá manipulação. Na verdade, como diz Valla, "há necessidade do controle político e da formação de bases eleitorais no seio de uma população com enorme potencial de luta, que é o favelado.” E eu ainda acrescentaria, no caso da Vila Operária, que ainda não era favela na década de 1960, não só o morador da favela, mas o pobre urbano em estado de vulnerabilidade social. Uma das formas de controle desse grupo é justamente afirmar que perpetuarão sua condição de classe inferior, pois a apatia e a ausência de interesse político são seus traços marcantes.

Dezenove de janeiro de 1960, José Correia da Rocha moveu uma ação de desapropriação indireta contra o município sobre o cemitério e o morro. Após um acordo judicial feito na Presidência do Tribunal de Justiça do Rio de Janeiro, que é a maior estância do Estado, foi acertado que a prefeitura pagaria pela terra. Ele disse:

Trinta e poucas parcelas de uns milhões de reais. Setecentos e poucos mil reais. O atual prefeito, José Camilo Zito dos Santos Filho, pagou algumas e não quis pagar mais. Então entrei, como prescreve a lei, com sequestro de recursos financeiros do município. Tem um mês que o sequestro saiu referente a 4 parcelas de setecentos e poucos mil cada 
uma. A prefeitura quitou a dívida com a família em uma escritura comum de compra e venda. Foi um processo pela justiça. A justificativa do município foi para fins sociais. Pode-se fazer este tipo de acordo para utilidade pública ou necessidade social. A prefeitura doou aos moradores a terra. Eu não sei se de forma oficial ou extra oficial.

Fica claro, por esse depoimento, que o morro no qual está localizada a favela Vila Operária não pertence mais à família Chadryky. A prefeitura é a legítima dona da localidade e tem como objetivo a manutenção do morador no local, já que alegou que a compra da terra da família seria para fins sociais. Nos relatos orais que gravei, não era isso que os moradores nos diziam. Afirmavam que já eram donos da terra, pois haviam recebido os títulos de propriedade das mãos do prefeito Hydekel de Freitas Lima, na década de 1980. Como utilizo a história oral, fui ao cartório do $5^{\circ}$ ofício, no $1^{\circ}$ Distrito do munić́pio de Duque de Caxias em 7 de novembro de 2001 e conversei com Nelson Nunes Braga, oficial de cartório, sobre a documentação referente à propriedade da terra na favela em questão.

O entrevistado disse:

\begin{abstract}
Não há documentação no cartório sobre a Vila Operária porque a área é posse. As pessoas vêm tentando utilizar o usucapião, mas a prefeitura de Duque de Caxias não autoriza. Em 1982, Hydekel de Freitas Lima deu títulos de propriedade, assinados por ele para alguns moradores, porém tais títulos não possuíam valor legal. Ainda hoje os moradores vêm ao cartório tentando obter o reconhecimento, pelo Estado, de seu imóvel. O atual prefeito reconhece as benfeitorias realizadas pelos moradores.
\end{abstract}

Na memória dos entrevistados, a propriedade já era uma realidade ao receberem o documento das mãos do prefeito. Porém, para a justiça, esse papel não tinha nem tem valor legal. $\mathrm{O}$ advogado José Correia da Rocha esclareceu:

Se o morador chegasse com a sentença transitada e julgada de Usucapião, aí seria diferente, porque Usucapião é um título judicial. (...) Apenas um morador poderia entrar na justiça, menos aqueles que tinham título. Estes não precisam de Usucapião, pois já são proprietários. (...) Muitos registraram no cartório do $5^{\circ}$ Ofício. Têm terrenos ali que já estão regularizados. (...) Eu não sei quantos, mas têm.

Em 2013, publiquei um artigo sobre a história desta favela, na Revista Pilares da História, editada pela Câmara Municipal de Duque de Caxias. O meu objetivo era que os leitores conhecessem esta história, mas que principalmente ficasse claro, que os moradores já possuíam o direito de posse sobre sua terra reconhecido pela Prefeitura da cidade de Duque de Caxias. Ao publicar que houve a venda da propriedade para a Prefeitura, um vereador da cidade, que é morador desde criança desta favela, foi conversar com o prefeito atual, Alexandre Cardoso, e levou o exemplar da revista a fim de comprovar que ele já sabia das negociações que não haviam sido compartilhadas com os moradores do lugar.

A História Pública entra no regime de visibilidade, portanto inseriu o discurso da posse da terra da favela na cena pública, fazendo com que houvesse um novo questionamento a respeito das ações da Prefeitura sobre a localidade. A favela é um espaço perene, portanto não é de longa duração, já que não há posse legítima. Não há garantias de que o indivíduo permanecerá ali, portanto a casa, os amigos, os vizinhos e até o próprio trabalho podem deixar de ser a qualquer momento.

A história que foi publicada despertou um sentimento esquecido em algum canto da memória, a territorialização, uma vez que desde a década de 1980, os moradores da Vila Operária não faziam qualquer manifestação que buscasse este reconhecimento. O espaço geográfico compreendido a partir destas novas narrativas reconstrói as raízes para o morador da favela que surgiu de uma ocupação, trouxe à tona o coletivismo praticado pelos primeiros habitantes, pois as histórias privatizadas, neste momento, reduziram seu significado, pois quando não houver nenhum tipo de comprovação sobre a ocupação do lugar pelo indivíduo, a narrativa pública do outro pode valer de confirmação perante o poder do Estado.

$\mathrm{O}$ artigo publicado teve como consequência a utilização de uma pesquisa histórica como documento para regularização fundiária. Baseando-se nele, o vereador traçou estratégias para conversar com o prefeito e com os moradores, a fim de determinar que medidas seriam cabíveis a partir deste momento que a história viva predomina se tornando um mecanismo de luta política e afirmação de sua identidade. 
Artigos

O vereador Osvaldo Lima declarou: "Posso dizer que conheço nossos problemas de perto, pois vivencio isto todos os dias. Tivemos muitas promessas, mas quase nada foi feito para os moradores. Agora a cidade vive um novo momento, e nós vamos poder chegar a conquistas importantes." Esta narrativa de resultados demonstra como a história pública tem poder de mobilização na medida em que provoca mudanças através do estímulo ao repensar as trajetórias a partir do Tempo Presente, pois o "publicar" agora fatos que marcaram determinado momento estimula a ampliação do olhar de quem viveu determinado fato.

\section{Bibliografia}

ALviTO, Marcos. Dos Parques aos Conjuntos. Entrevista a Rosilene Miliotti, em www.observatoriodefavelas. org.br. Acesso em: 10 maio. 2010.

CARONE, Edgar. O PCB. V.3(1964-1982). São Paulo: Difel,1982, p. 22.

COSTA, Rogério H. da. O mito da desterritorialização: do "fim dos territórios" à multiterritorialidade. Rio de Janeiro: Bertrand Brasil, 2011.

VALLADARES, Lícia do Prado. A Invenção da favela. Do mito de origem a favela.com. Rio de Janeiro: FGV, 2009, p.24 e p.26.

PEREIRA, Tatiana Silva. Imaginário Espacial e Discurso: o caso das favelas cariocas e o noticiário dos jornais. Rio de Janeiro, 2000. 227 fls. Dissertação (Mestrado em Ciências) Instituto de Geociências, Universidade Federal do Rio de Janeiro, 2000, p. 12.

POLLAK, Michael. Memória e Identidade Social. Estudos Históricos, Rio de Janeiro, vol. 5, n. 10, 1992, pp. 1011.

RICCOEUR, Paul. A memória, a bistória, o esquecimento. Campinas, SP: UNICAMP, 2007, p.131.

VALLA, Victor Vincent (Org.). Educação e Favela Políticas para as favelas do Rio de Janeiro, 1940-1985. Rio de Janeiro: Vozes, 1986, p. 47. 